\title{
The Concept of Energy Conservation in Architectural Design and the Creation of Modern Thai Architectural Identity
}

\author{
By Rungrat Tengkaoprasert*
}

\begin{abstract}
The concept of energy conservation is not only a part of green architectural design, but also an important element in the creation of a Thai architectural identity. The objectives of this research are to 1) review and collect theories and concepts of energy conservation in architectural design from academic papers; 2) conduct surveys of architecture in various regions in Thailand, which are prominent and relevant to this concept; and 3) interview professional and academic architects. The results of this research. "The concept of energy conservation in architectural design within a Thai context," consists of five fundamental principles as follows: 1) passive design, such as building ventilation and natural lighting; 2) active design, such as building climate control and optimization of electrical equipment and appliances; 3) usage of green areas in Thai architecture, such as tree plantations inside or around the building, vertical gardens, roof gardens and reducing or replacing impervious surfaces by plants; 4) design following function and utilization by grouping functional areas or zoning from natural zones, passive zones, semi-passive zones and control zones in buildings; and 5) construction method design, such as reducing the quantity of material use and construction waste and introducing the use of low environmental impact materials. According to the results of this research, professional and academic architects mainly focus on two principles: passive design and design follows function, while only a few integrated all five principles. Furthermore, the interviewees perceived that "semi outdoor/indoor space" or "grey area" is a climatic responsive design that plays an important role in Thai architectural identity. In conclusion, an analysis of several case studies showed that passive design, use of green areas, and design following construction processes are the major design principles of Thai architecture that transformation but still cohere.
\end{abstract}

\section{Introduction}

After the industrial revolution (1750 -1850), the concept of overcoming nature with scientific knowledge created many innovations in the world. The world's economy was growing stronger, increasing employment, productivity and spending. This lasted until the energy crisis period (1970s), when discussions built regarding the oil crisis (1973) and environmental crises, such as the greenhouse effect, ozone hole, urban heat island, acid rain and, especially, climate change. This situation has created increased energy consciousness.

An architectural society should be aware of and responsible for the environment by designing architecture with energy conservation, which integrates scientific knowledge and local wisdom, in mind. The people in

*Assistant Professor, Thammasat University, Thailand. 
Southeast Asia and Thailand often coexist with nature. Their settlements are often on the edge of a river, so the houses are elevated, allowing for floods, and in the shade of trees, as in Figures 1 and 2.

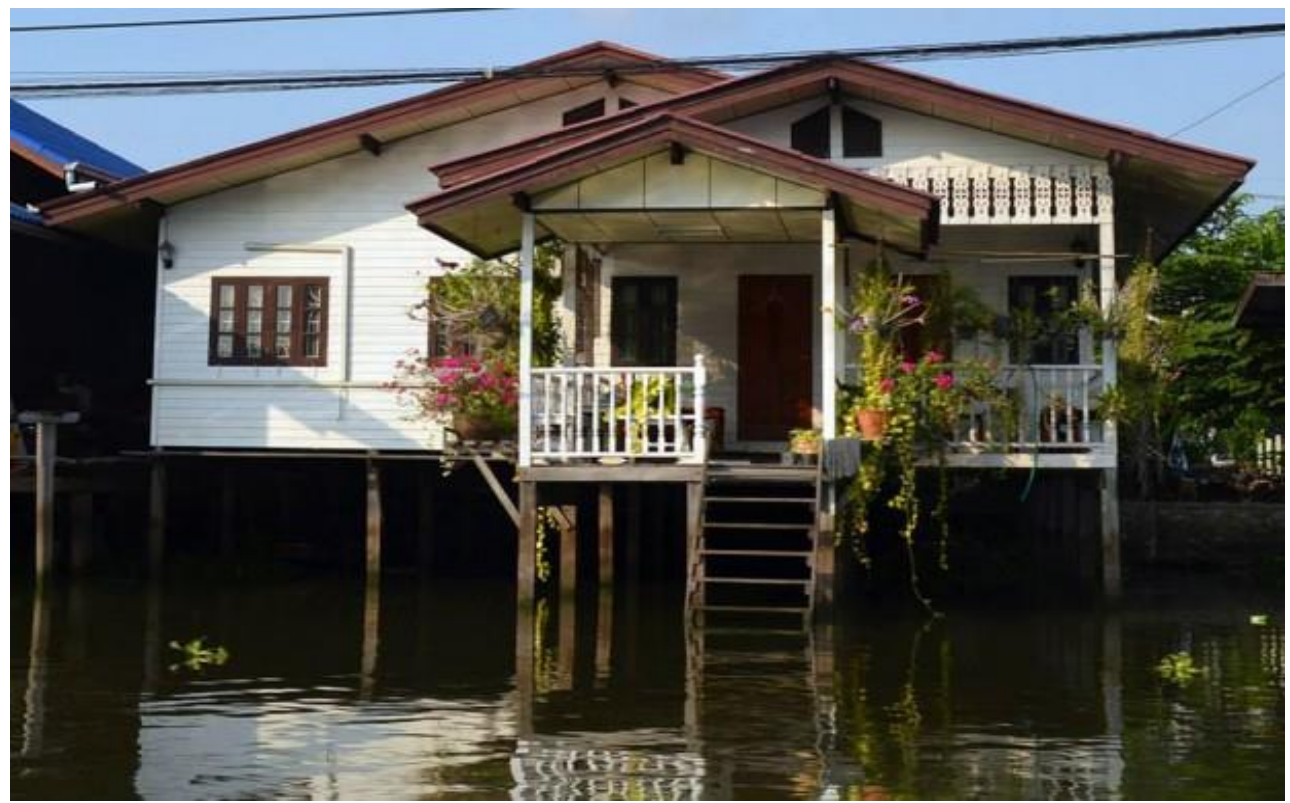

Figure 1. Thai House Located at River Front, Bangyai, Bangkok, Thailand; The Entrance Located to the River

Source: Wongprasert, Ratchaneekorn, 2014.

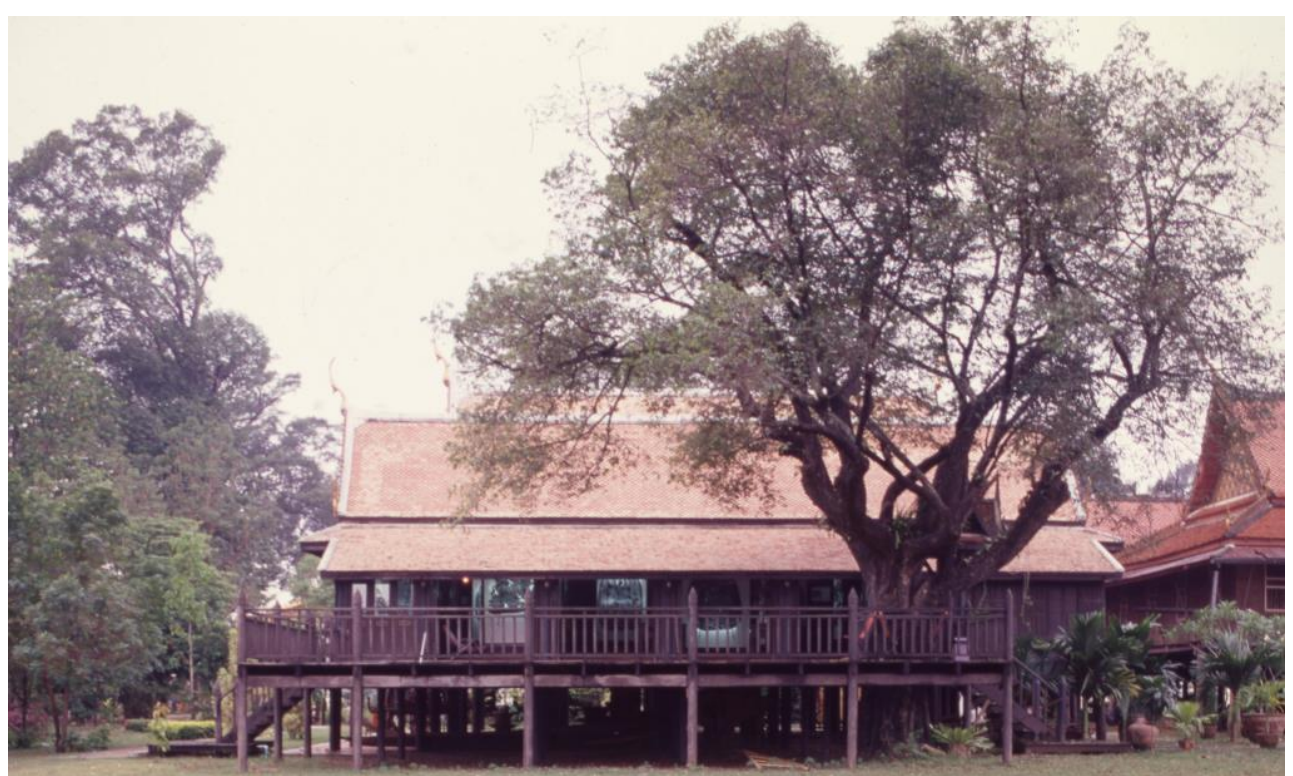

Figure 2. Big Leather Museum, Khanon Temple, Ratchaburi ${ }^{1}$

Source: Inpantang, Vira, 2011.

1. Traditional Thai House: one of the many special architectural elements was a big tree in the courtyard: Build a House and Plant a Tree. 
"In the United Kingdom, some $40-50 \%$ of the national consumption of primary energy is used for building service." 2 As in other countries, more than half of energy consumption is spent on buildings, especially in capital cities. Energy conservation for buildings, in addition to reducing the cost of the building, also reduces the overall energy consumption, and thus the environmental impact.

The concept and hypothesis in this research, namely that Thai architecture in the past was designed to be environmentally responsible with low energy consumption and low environmental impact, is representative of a key issue within energy conservation. The study looks at the concept of energy conservation in architectural design and the creation of modern Thai architectural identity, as part of a research project on green architecture and sustainable development, which observed concepts and principles of energy conservation and Thai architectural identity from the past to the present. The result of this research will be a guideline to design a modern Thai architecture, that suitable for present economic, social and also be responsible for the environment.

\section{Literature Review}

In the past, Thai people settled near the river because it was convenient for living and transportation. Thai architectural identity consists of wooden houses, raised basements, courtyards and trees in or close to the building. They are divided into indoor space, semi-indoor space and outdoor space. The living area in a Thai house has an eaves space and a terrace with big trees, and the area for living can be used in comfort without energy, as in Figure 3.

2. Randall Mcmullan, Environmental Science in Building (New York: Palgrave Publishers Ltd., 2002), 345. 


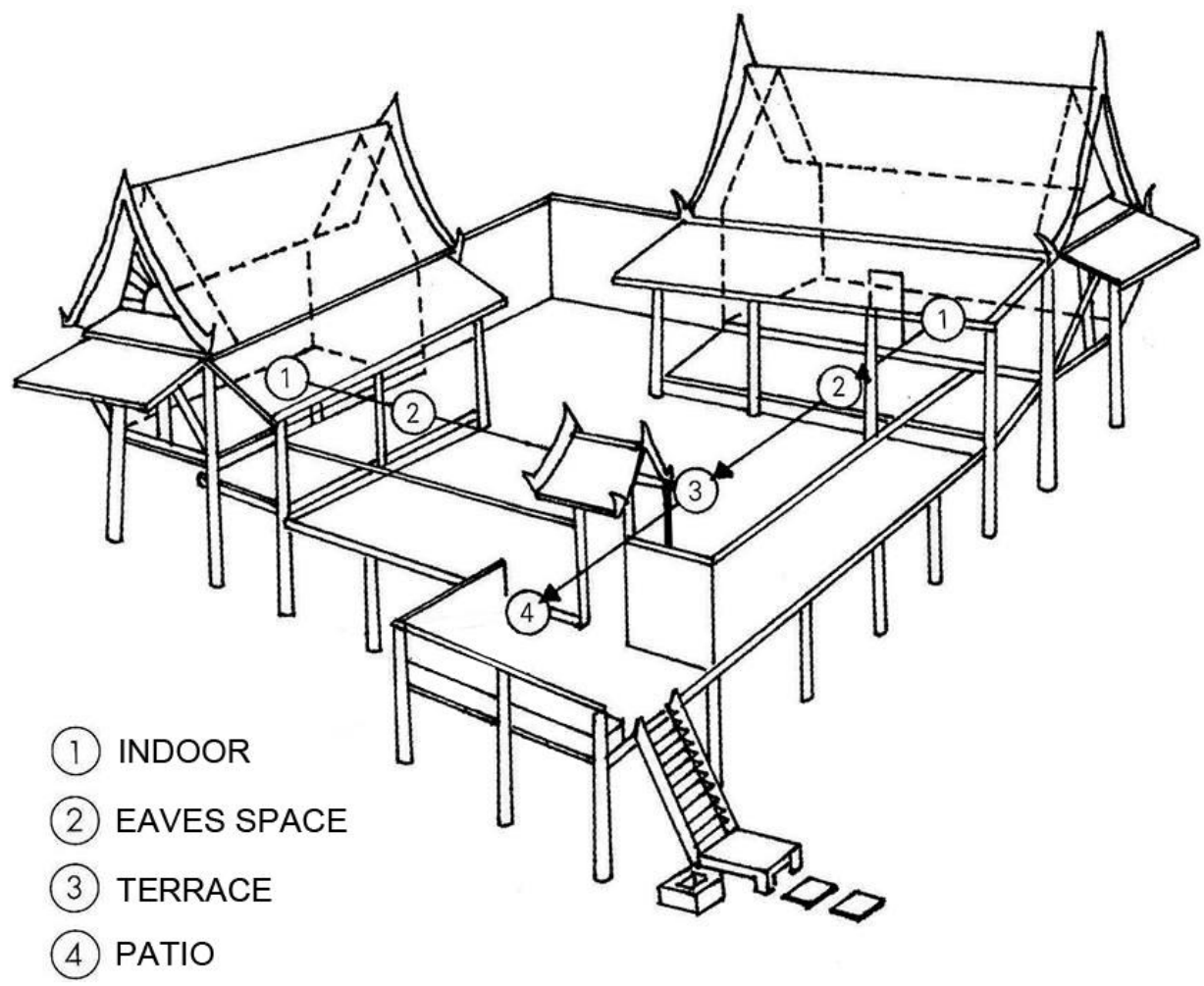

Figure 3. Traditional Thai House, in Some House was plant a Big Tree in Courtyard or Terrace, that for Thermal Comfort

Source: Adapted from Jaijongrak, Ruetai, 2000. ${ }^{3}$

The concept of energy conservation in architectural design utilizes integrated technology, as well as scientific and local wisdom, in order to reduce energy consumption and to create a comfortable zone. Givoni identified the four principles of comfort zone creation, ${ }^{4}$ as follows:

Ventilated Cooling is the principle of cooling with cool air through, when the wind through the occupiers will cool down.

Radiant Cooling is the principle of temperature transfer at materials' surface. This can be applied with a building envelopment, for the appropriate temperature transfer at an appropriate time and function area.

Evaporative Cooling, when water evaporates, draws heat energy from the environment to reduce the temperature. Therefore, there are increases in the spray in the air and evaporation. When the water evaporates, the temperature decreases.

Cooled soil as a cooling source for the building, at a depth of 2-3 meters from the surface, the soil is at a lower temperature, which means that the

3. Ruetai Jaijongrak, Ruen Thai Derm (Bangkok: Thammasat University printing house, 2000).

4. Baruch Givoni, Passive and low energy cooling of building (New York: Van Nostrand Reinhold. 1994), 3-19. 
soil can be a cooling source. However, this principle is rarely found and applied in Thailand.

When the weather is hot, people often stay in air-conditioned areas. Electricity consumption for air conditioning systems accounts for at least half of the total power consumption of buildings. Therefore, the concept of energy conservation in architectural design should to apply to all processes of a project life cycle from the design stage to the construction stage, occupancy stage and renovation stage. This research compiles the principle of architectural design for energy conservation in five ways.

\section{Passive Design Concept}

Passive Design is the concept of building structures based on the principle and potential of natural energy to create a comfort zone for the occupant. Natural ventilation and natural lighting are the most natural energy applications in this design.

\section{Natural Ventilation}

The three methods of designing architecture can be applied with natural ventilation for creating a comfort zone.

Ventilation through various openings may occur by designing a building with openings or using a brick vent to allow the air through.

Ventilation through the space under a house is found in Thai architecture and throughout Southeast Asia. The houses are usually raised in the basement due to the settlements being in flood areas, and that space allows good wind flow.

Ventilation through the space under the roof, which is a heat storage space, needs to be vented through ventilators.

Figure 3 shows the elements of a traditional Thai house that have been designed to allow the wind to blow through in a variety of ways. The semiindoor areas and outdoor area are the living spaces between daytime, which also express traditional Thai life style.

\section{Natural Lighting}

In the application of lighting design in buildings, direct lighting and indirect lighting depend on functional areas, because heat comes with light, which increases the load on the air conditioning system. Designers must use the appropriate design techniques to account for this. This paper has compiled four approaches to the use of natural light in a building: light from the side of the building, light from the top of the building, light through the hallway or 
large openings, and reflective surfaces or lighting sheets. ${ }^{5}$ These methods rely on technology and architectural elements to reduce heat radiation or glare, such as a shading device for light filtering, tree planting and low emissivity glass, which allows light to pass through but filters heat energy.

In Thai architecture design concepts, natural light and ventilation have been integrated by designing the light from the top and sides, and raising the basement for the wind to pass through, as in Figure 4.

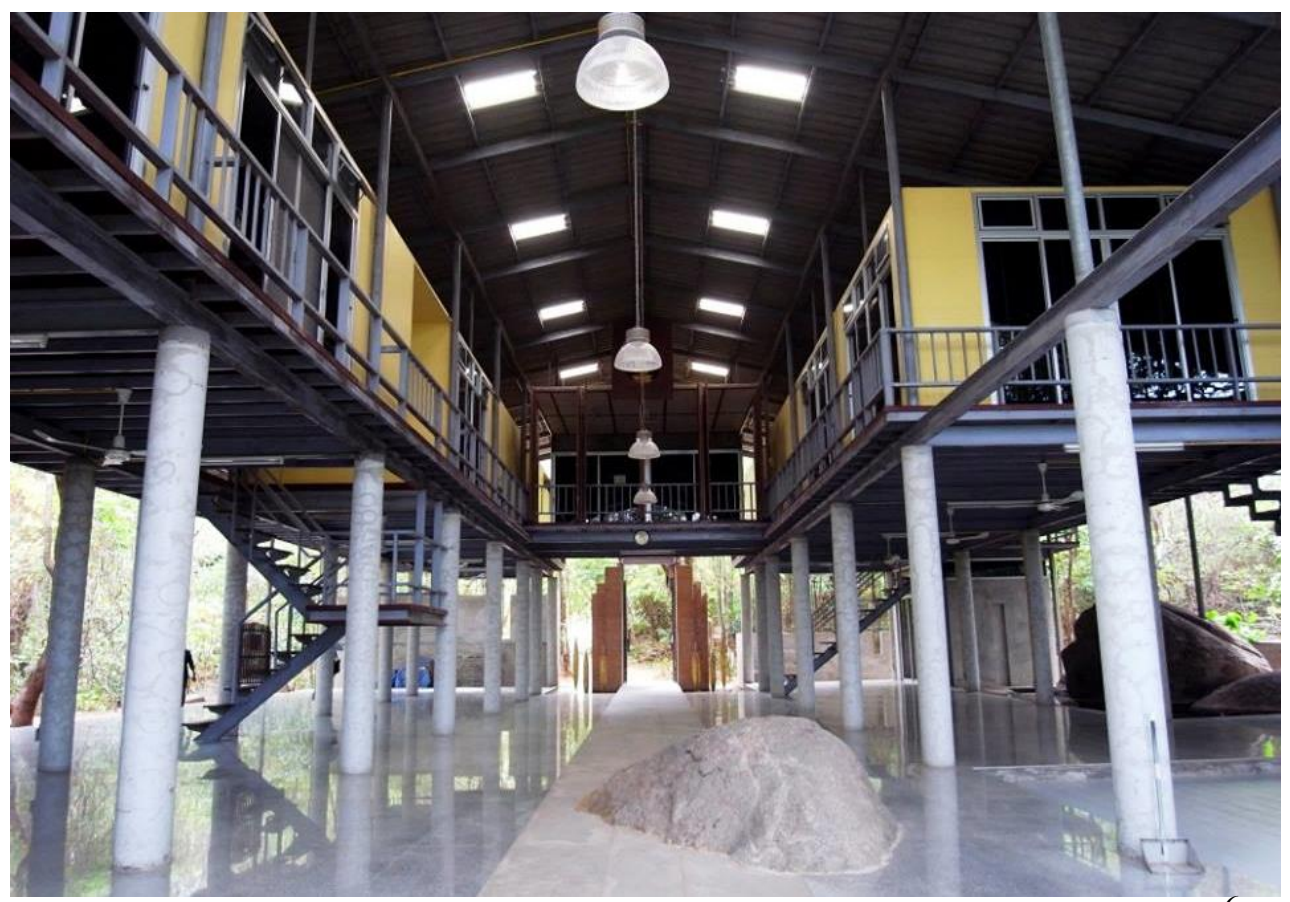

Figure 4. Temple Women's Shelter, Wat Pa Wachira Banphot, Chonburi ${ }^{6}$

Source: Prasertsuk, Santirak, 2011.

\section{Active Design Concept}

Active Design is based on technology or innovation that saves energy. Boonyatikarn (1999) said "The design of energy-saving buildings should use the most benefit of natural potential, while seeking the least energy-consuming processes and technologies to enrich quality of life without compromising the environment". The case study is collected as follows.

5. Awiroot Srisutapan and Panjira Tisawipat, Daylight in Architecture (Patumthani: Thammasat University Printing, 2009), 49-59.

6. This shelter was designed with small skylights and a raised high floor, so that natural light and wind would enter the building. During the day, this building uses little energy. So, these architectural elements make the occupiers feel comfort. 


\section{Case Study of Air-conditioned Area}

The main source of energy consumption is temperature adjustment. Therefore, the method of reducing energy consumption of the air conditioning has to integrate aspects of specific knowledge. The basic principle is that "Allowing outside air to leak into the building results in huge amounts of energy loss" (Boonyatikarn 1999). Therefore, the air temperature control in air-conditioned areas has to control air leakage and control the relative humidity. In Thailand, the average relative humidity is $72-74 \%{ }^{7}$ while the appropriate relative humidity is $40 \% .^{8}$

Figure 5 shows the working principle of a general air conditioner and an air conditioner with a heat pipe. In general, air conditioning acts to reduce temperature and humidity, so the cooling coil in the air conditioner is modified by adding the heat pipe, optimizing it for dehumidification and energy efficiency. Another way to increase the energy efficiency is to turn on the air conditioner all day ( 24 hours), because a constant temperature will reduce the cooling load.

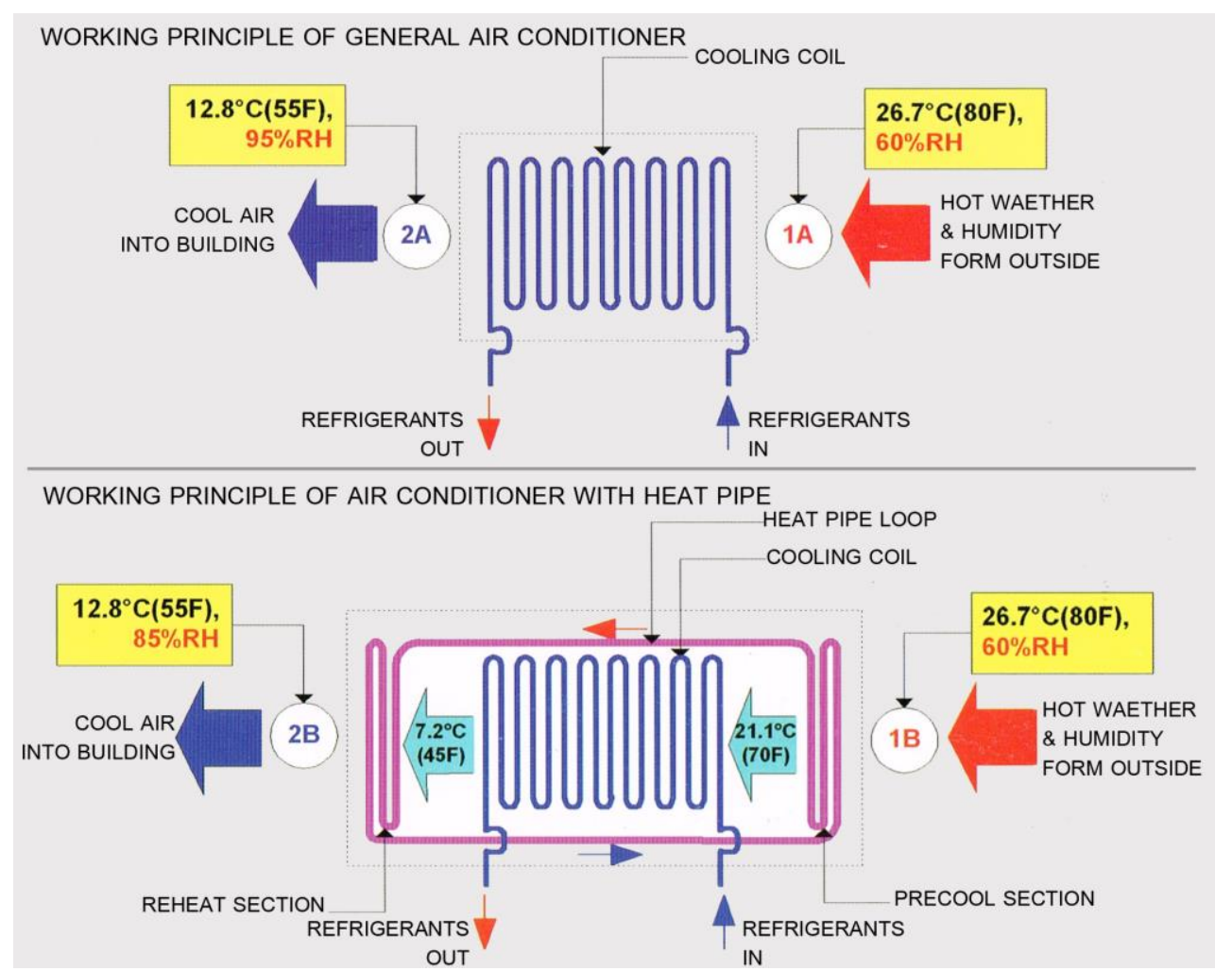

Figure 5. Comparison of Working Principle of General Air Conditioner and Air Conditioner with Heat Pipe

Source: Boonyatikarn, Soontorn, 1999.

7. Department of Meteorology, Relative Humidity.

8. Soontom Boonyatikarn, Energy efficient home design technique for better quality of life (Bangkok: Property market co., ltd, 1999). 


\section{Case Study of Optimization of Electrical Equipment}

Currently, the development of energy efficient appliances, such as energysaving appliances and longer-lasting LED lights, use less power and less heat. In addition, elevator systems in high-rise buildings, when they are intelligent systems, can calculate and identify which lift to send to the callers. This increases the efficiency of the transportation and saves more energy in the building.

\section{Green Concept}

Many large trees can reduce temperatures in the daytime as the trees use solar energy and the environment to live. They also absorb water from the soil and convert it into steam that is lost from the leaves. These processes use about 2,200 BTU of thermal energy to convert one liter of water into steam, so a big tree can absorb water from the soil and convert it into steam at about 65 liters/day, which means big trees can reduce the heat in the environment equivalent to air conditioning of 12,000 BTU/hr (daytime is $12 \mathrm{hrs}$.). Thus, temperature reductions can be created by planting trees and building appropriate environments, as shown in Figure 6.

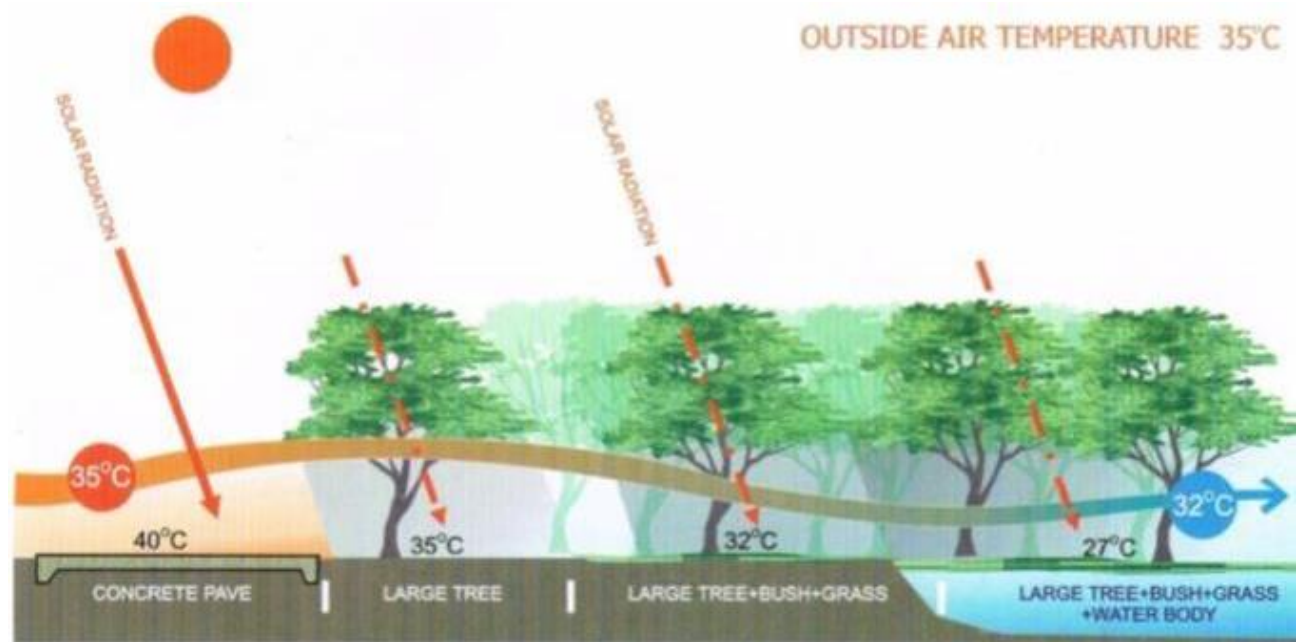

Figure 6. Diagram Showing Group of Large Trees Absorbing Solar Radiation, when the Wind through the Bush is Absorbed and Reduces the Hot Temperature Source: Boonyatikarn, Soontorn, 2002. ${ }^{9}$

In the past, the Thai style garden had no clear form or order, and was unrecognized amongst the Chinese Garden, Japanese Garden, Spanish Garden and French Garden. However, Sukawattana (1996) collected and explained

9. Soontorn Boonyatikarn, Integrated Design Approve: Shinawatra University. (Bangkok: G M Max Media, 2002). 
the green areas of Thailand in two categories: functional green area and vegetation green area. ${ }^{10}$ The details are as follows.

\section{Functional Green Area}

(1) The Royal Garden: the king's garden is a private, natural and cleanly decorated area, located outside the city wall.

(2) The Public Park: this was rarely found in Thailand in the past. In addition to the "Sugar Palm Forest", the king provided a public hearing area and a Dharma area.

(3) Landscape: often found in only palaces and temples, the composition of the space often uses bonsai, potted plants and artificial mountains. This area is for ceremonial and religious purposes.

(4) Water Garden: this was formed with the digging of the pond for consumption, after which they began to plant lotus for beauty and the worship of Buddha.

\section{Vegetation Green Area}

(1) Large perennials, or sacred trees, was often planted in the courtyard or around the house in some direction according to the principle of faith.

(2) Medium and small perennials are trees planted for food and for shade. These trees, such as mango, jackfruit, longan, etc., are commonly located in the middle of a courtyard.

(3) Flowers and bushes, planted in the ground and in pots, were mostly planted on entrance stairs and around fences as aesthetically pleasing symbols of hospitality. This vegetation was usually fragrant. In the case of the potted plants, these show the social status of the wealthy and are located in the space under the eaves and patios.

(4) Vegetables and herbs, planted for food and for body treatments, were commonly planted in the backyard or around fences.

The objective of planting in traditional Thai architecture was to provide shade for living spaces, relief from high temperatures, food and symbols of belief and ceremony. There are many types of planting that have been found to be related to Thai architecture, such as planting trees in the middle of a courtyard, planting big trees near and around the house, planting trees in a natural water resource or pond, and planting trees in pots, etc.

\section{Grouping Functional Area Concept}

Behavior and building occupancy have a significant impact on energy consumption. In the design stage, the architect might design and plan to the

10. Kaiseang Sukawattana, Suan Thai (Bangkok: Chulalongkorn University printing house, 1996). 
owner's requirements or some assumptions, but after the building has been passed to the occupants, they might have different behaviors or create new functions. Therefore, the building manager should follow, monitor and analyze the behaviors for managing the efficiency of energy and the area. The principle of grouping functional areas for energy management should be performed according to the activities described in Table 1.

Table 1. Groupings of Functional Areas, Categorized by Activities and Level of Thermal Comfort

\begin{tabular}{|l|l|l|}
\hline \multicolumn{1}{|c|}{ Zone } & \multicolumn{1}{|c|}{ Detail } & Activities and Function \\
\hline Natural Zone & $\begin{array}{l}\text { Outdoor area. } \\
\text { Weather changes all the time. } \\
\text { Landscape can be designed to be } \\
\text { comfortable. }\end{array}$ & $\begin{array}{l}\text { Casual activity such as } \\
\text { walking, sitting and } \\
\text { exercising. }\end{array}$ \\
\hline Passive Zone & $\begin{array}{l}\text { Semi-indoor areas that rely on natural } \\
\text { and architectural elements to prevent } \\
\text { environmental influences, but still rely } \\
\text { on natural energy, such as wind and } \\
\text { natural light. }\end{array}$ & $\begin{array}{l}\text { Canteen } \\
\text { Multi-purpose hall }\end{array}$ \\
\hline $\begin{array}{l}\text { Semi-Passive } \\
\text { Zone }\end{array}$ & $\begin{array}{l}\text { Indoor area, uses a mechanical control } \\
\text { system for comfort zone. } \\
\text { Transition area between passive zone } \\
\text { and control zone. } \\
\text { Temperature transition area. }\end{array}$ & $\begin{array}{l}\text { Corridor } \\
\text { Casual working area } \\
\text { Rest area }\end{array}$ \\
\hline Control Zone & $\begin{array}{l}\text { Indoor area, where mechanical } \\
\text { dependencies completely control. }\end{array}$ & $\begin{array}{l}\text { Concentration area, such } \\
\text { as meeting room and } \\
\text { working area. }\end{array}$ \\
\hline
\end{tabular}

Source: Adapted from Boonyatikarn, Soontorn, 2002.

\section{Construction Method Design}

In addition to considering the orientation, functional zone, passive and active designs, material production and the construction process that creates waste and impacts the environment, architects must be aware and environmentally responsible in the building design stage.

The Thai Green Building Institute, under the supervision of the Thai Green Building Foundation, has set up a green building gauge system called "Thai's Rating of Energy and Environmental Sustainability (TREES)."11 TREES for New Construction and Major Renovation Version 1.1 (TREES NC Version 1.1) states in Division 5: Materials and Resources, which are divided into three sub-divisions:

(1) Reduce new materials by maximizing the use of existing buildings or by reusing materials.

11. Thai Green Building Institute, Thai's Rating of Energy and Environmental Sustainability for New Construction and Major Renovation (Bangkok: TGBI, 2013). 
(2) Reducing construction waste should start at the beginning of the design stage, construction stage and should manage waste and separate the types of waste.

(3) Use of low environmental impact material, environmentally friendly material, natural materials and local materials should contribute to lower the energy consumption for transportation.

Traditional Thai Architecture belongs to the energy conservation buildings, with the principle of passive design concepts, such as using natural lighting and ventilation, planting trees to reduce the temperature and also construction design methods, such as material production and timber modular system.

The case study of the Lanna Rice Barn Homestay in Chiangmai showed that owner Adul Heranya collected 20 ancient rice barns, which were adapted to be a homestay. ${ }^{12}$ A Thai vernacular house is a building that can be dismantled and transported, because the use of materials is cost-effective and re-uses buildings. This ability is representative of the culture, knowledge and wisdom of the Thai ancestors (see Figure 7). That also complies with the TREES criteria for the division of materials and resources, reducing the new materials and reducing the construction waste. Therefore, the Thai vernacular architecture is a unique architecture that is environmentally friendly and compatible with nature.
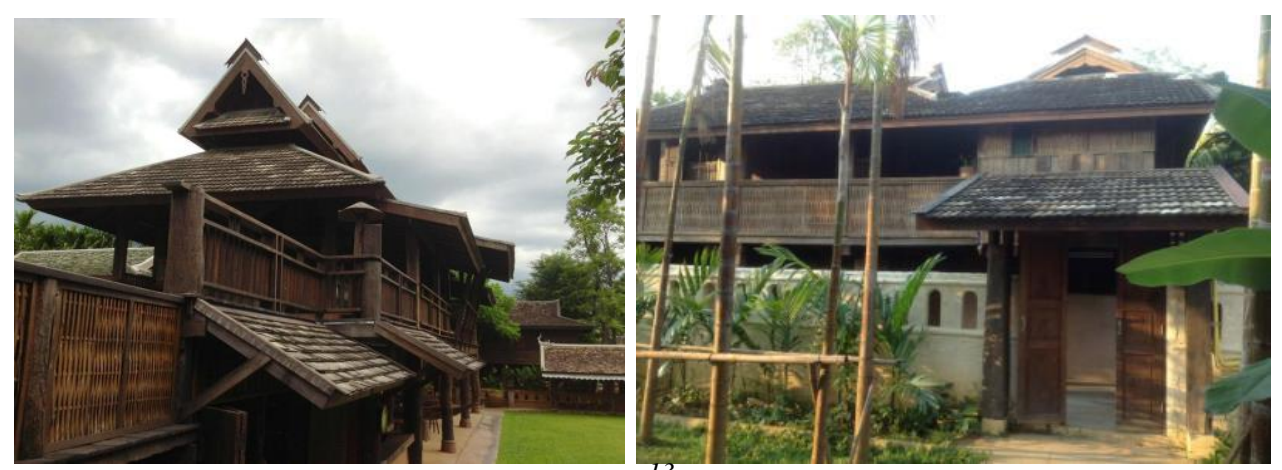

Figure 7. Lanna Rice Barn Homestay ${ }^{13}$

Source: Heranya, Adul, 2013.

The principles of energy conservation, compiled from documents and textbooks, show that most energy-saving designs follow the same principles as the Thai architectural design derived from the wisdom of ancestors. In the project life cycle - from the feasibility study, programming, design, and construction to occupancy and renovation - all processes should be planned and designed with the concept of energy conservation.

12. I-Urban, Lanna Rice Barn Homestay, 2013.

13.This building was adapted and re-built form Rice Barns, in Thai Vernacular Architecture. 


\section{Methodology}

The main steps and the scope of the research are summarized below.

\section{Study of Concept of Energy Conservation Architecture}

Theoretical studies from academic papers define the principle of architectural design for energy conservation. These include case studies of relevant architectures by analyzing architectural elements that express "inheritance" or "transformation" from Thai traditional architecture.

\section{Conducting Surveys of Architecture}

Conducting surveys of architecture in various Thai regions depends on the list of architectural sites determined by the research committee. These cover the architectural case studies in Step 1 and the distinctive characters that correspond to the concept of the research.

\section{Interviewing Professional and Academic Architects}

Both professional and academic architects were interviewed as they were the architects who designed the buildings in the surveys. Interviews were conducted to find the ideas and inspirations for the design, as well as to understand the creation of modern Thai architectural identity.

\section{Integrative Data Analysis and Discussion of Results}

Integrated data analysis, field surveys and interviews with professional architects and academics led to the results of this research. The results of this research were discussed with the research committee, leading to the point of "inheritance" or "transformation" from Thai traditional architecture under the concept of energy conservation for present and future societies.

The analysis of Thai architectural identity related to the concept of energy, which can classify the architectural elements by "inheritance" and "transformation", defined as: ${ }^{14}$

Inheritance refers to the continuation of the pattern, materials and traditional construction methods, in accordance with their beliefs, ways of life and traditions. There are levels of "inheritance," and lower levels may be the beginning of a transformation.

Transformation refers to changes in the pattern, materials and new construction methods that are based on the climate, beliefs and some traditions. These are the patterns that reflect the basic abstract and the present social context.

14. Vimolsithi Horayangkura, Boosakom Settaworakit and Vira Inpantang, The Creation of Modern Thai Architectural Identity: Fundamentals of Thai Architectural Identity (Bangkok: JBP Center Co., Ltd., 2015), 4-95. 


\section{Results}

The results from this research came from two sources: sampling and interviewing with professional and academic architects. The results are based on combining principles and theories, as follows.

\section{Results of Sampling}

Integrating the analysis data led to discussion and conclusions about the architectural elements under the concept of energy conservation. This produced a classification of the architectural elements by "inheritance" or "transformation", based on the principle of architectural design for energy conservation in five ways.

\section{Passive Design Concept}

The case studies found five architectural elements:

Ventilated walls

Elevated floors

Space under the roof / Eaves space

Shading devices

Small skylight

The architectural elements are designed to rely on natural energy and create "semi-indoor space" for the living area in the Thai lifestyle.
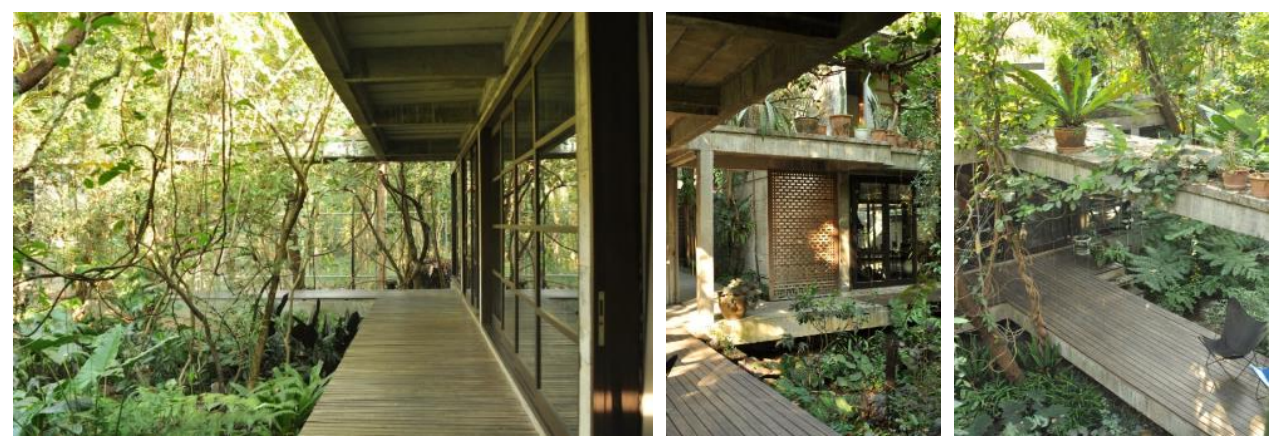

Figure 8. Rirkrit Tiravanija's House, Gradually Built by Existing Budget and Avoiding Existing Trees ${ }^{15}$

Source: Tengkaoprasert Rungrat. Settaworakit, Bootsakorn and Horayangura, Vimolsithi, 2011.

15. The architectural element of this house contributes to the semi-indoor space distributed around the house. It also has the appearance of the elevated floor, receives the natural light. And one important is the concept of maintain the existing trees that make the house shady and reduce the temperature. 
The case studies of inheritance were "Rirkrit Tiravanija's House" (see Figure 8), "Dharma House" (see Figure 10) and "Lanna Rice Barn" (see Figure 7). The common physical aspects were an "elevated floor" and "some ventilated walls". Due to the space created from those elements, the user can live without air conditioners.

The case studies of transformation were "Tonkhoa Panin's House" (see Figure 11), "Panyaden International School", "Temple women's shelter, Wat pa Wachira Banphot" (see Figure 4), "Operation Building of the Faculty of Economics, Kasetsart University", "Mahidol Learning Center" and "Chulabhorn Graduate Institute Building”. The buildings' physical constructions used modern materials. Most of the buildings are public buildings with complex spaces, but they still have physical features that reflect the Thai architectural identity, such as the elevated floors, the small sky light and use some ventilated materials.

\section{Active Design Concept}

Architects have to integrate their knowledge of different building technologies and decide on a selection of architectural elements, such as "automatic-shading devices", "efficient air conditioners" and "innovation of electric appliances", etc.

The conclusions from the case studies related to aspects of the active design concept showcasing Thai architecture identity as a transformation from the past, such as:

The Kasikorn Business-Technology Group (KBTG) Building is Thailand's first financial institution office building to be awarded a LEED-NC Platinum certification in the category of new construction or major renovation. The building envelopment is "Insulted Laminate." Moreover, the open floor plan allows natural light through and uses special air conditioner technology, which saves energy. The building can save 50 percent of the water supply, because it has a water treatment system for reuse.

In the Bio Solar House, architect Soontorn Boonyatikarn integrated his knowledge of energy saving mechanisms with architecture design. The Bio Solar House saved 15 percent of the general building energy consumption. The important technique here was the efficient solar cells on the tilted roof at 35 degrees, and the tilted roof at 25 degrees for trapping the water and the dew into the rain gutter through a vertical channel into the sand pond to filter the water, so that the house does not have to rely on a water supply, and also uses the treated water. He created a green environment with trees for shading, which control the climate around the house, as in Figure 9. 


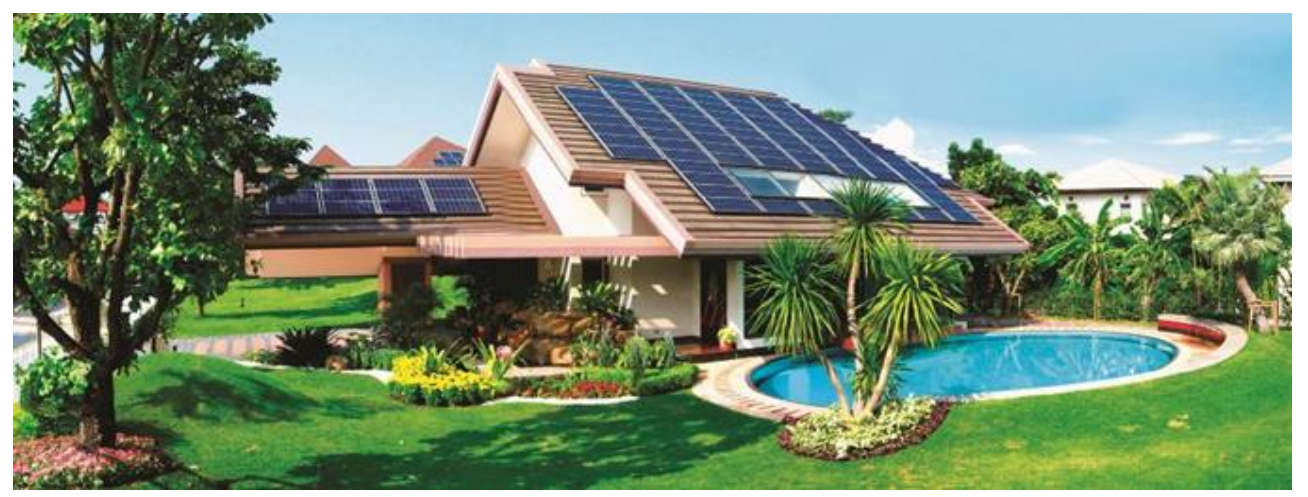

Figure 9. Bio Solar House

Source: Boonyatikarn, Soontorn, $2004 .^{16}$

\section{Green Concept}

The green area or planting area can be created in various patterns.

The physical characteristics of the case studies included planting large trees in the terrace, planting trees around the building, paving the turf block, vertical garden and roof garden.

The case studies of inheritance were "Dharma House" (see Figure 10), "Rirkrit Tiravanija's House", "East House", "Arsom Silp Institute of The Arts", "Temple women's shelter, Wat pa Wachira Banphot" and "Mahidol Learning Center". These had "the big tree in courtyard" and "trees around and inside the building".

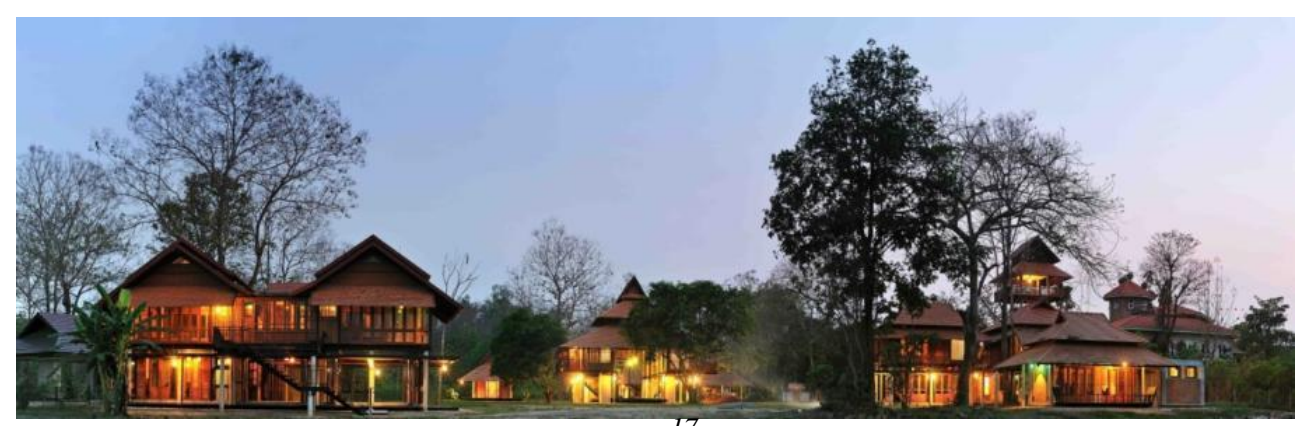

Figure 10. Dharma House, Chiangmai ${ }^{17}$

Source: Faculty of Architecture, Chulalongkorn University alumni association, 2011. ${ }^{18}$

The case studies of green concepts of transformation were "Rachamankha Hotel" and "Operation Building of the Faculty of Economics, Kasetsart

16. Soontorn Boonyatikarn, Bio-Solar home: It is power by the Sun (Bangkok: Chulalongkorn University Press, 2004).

17. This is a place for a big family to live in and is designed for several functions, such as office space, Dharma pavilion, observatory and bedroom pavilion. This house does not use air conditioners, but it is comfortable because of the old big tree that creates shade and reduces the temperature, while the architect created a gray area from shade for the architectural elements, such as patio, terrace, eaves and elevated house.

18. Faculty of Architecture. Chulalongkorn University Alumni Association. $a+A 07$ : Dharma House (Bangkok: Amarin Printing \& Publishing Pcl., 2011). 
University". These had planting patterns following "vertical garden", "roof garden" and "turf block".

\section{Grouping Functional Area Concept}

The grouping of areas occurs based on activities and hierarchy from "natural zone" to "control zone". This also seems to be part of the traditional Thai architecture, including a hierarchy from "courtyard" to "eaves space" until "indoor space". However, the case study of transformation was "Shinawatra University Buildings".

\section{Construction Method Design}

In the construction process there is a lot of waste, but Traditional Thai Architecture is built from natural materials, such as wood, and knocking down the system causes less waste. This stems from an understanding of the limitations and properties of the materials, which is different to the general construction. The samples designed with inheritance were "Dhrama House", "Lanna Rice Barn", "Arsom Silp Institute of The Arts" and "Panyaden International School".

\section{Results of Interviews with Professional and Academic Architects}

The interviews showed that most architects mainly focus on the passive design concept and the grouping functional areas concept. Some architects had a comprehensive design concept of energy conservation, which integrates all energy-saving approaches together. This includes the architect Soontorn Boonyatikarn, who integrated a variety of ideas about energy saving to design a home energy-saving facility with about 15 times that of a typical building. On the other hand, when Architect Chaiwat Limwattananon was interviewed about the architectural design of his firm, it was mainly the concept of energy conservation, such as "The Kasikorn Business-Technology Group (KBTG) Building," which was approved by the LEED Platinum certification.

The outstanding case study that integrated energy-saving approaches is "Tonkhao Panin's House," as in Figure 11. 

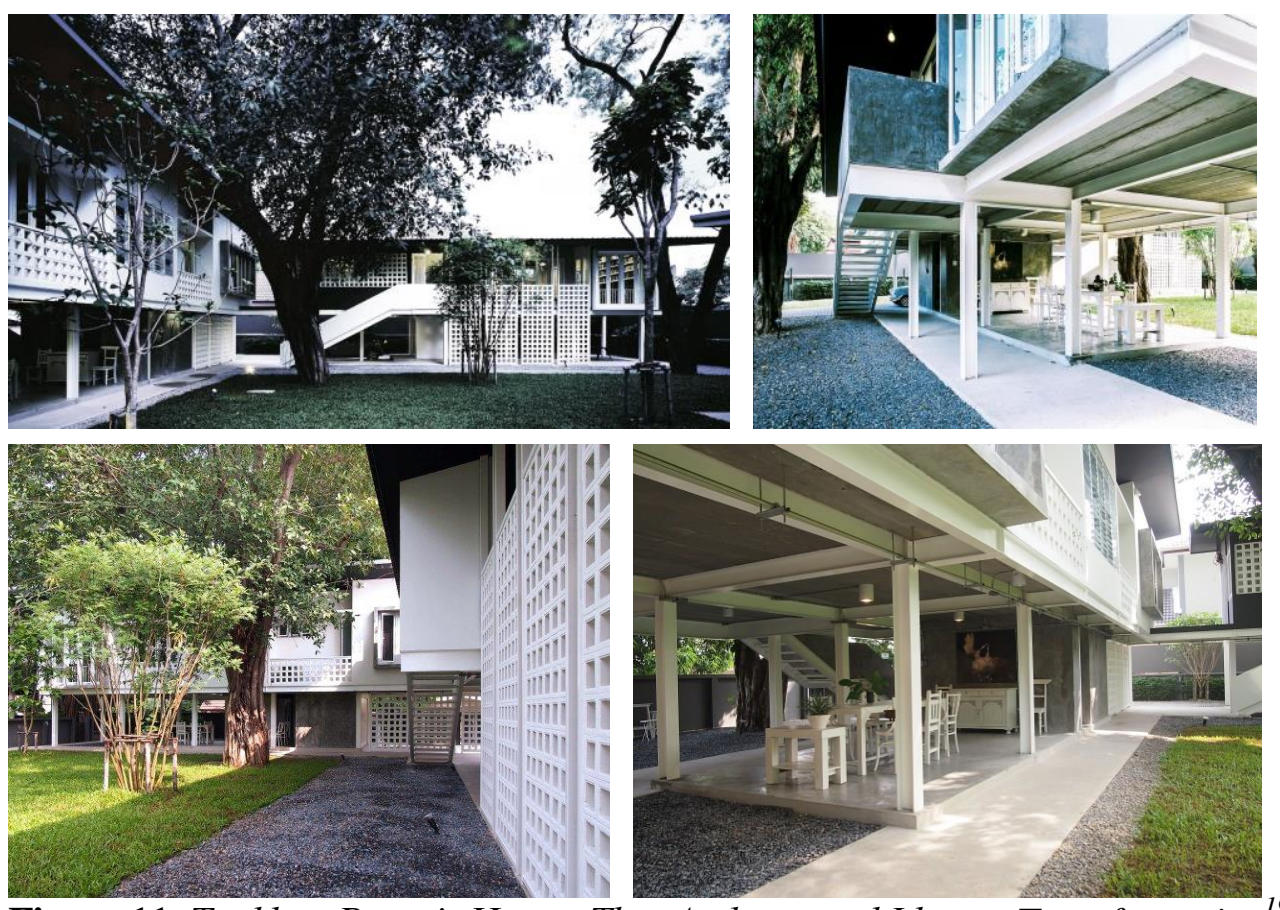

Figure 11. Tonkhao Panin's House, Thai Architectural Identity Transformation ${ }^{19}$ Source: Panin, Tonkhao, 2013.

\section{Discussion}

Traditional Thai architecture is created for living in thermal comfort that is designed for a warm humid climate and almost does not consume energy. Presently, the way of life is changing due to economic, social and technological improvements, so this research proves the Thai architectural identity that is consistent with the concept of energy conservation and that is appropriate to the climate. In addition, this concept can be applied from the beginning of a project lifecycle until post occupancy. As well as the energy conservation, the creation of comfortable conditions and the efficiency of building applications are important considerations for the designer to consider. In addition, public buildings in Thailand are usually not closed, but often semi-open buildings, so there is no control weather, which are often. These are the factors that make architects to have to create space for thermal comfort if possible.

\section{Conclusions}

To sum up, the architectural elements of energy conservation for inheritance are: "Elevated Floors", "Terrace or Semi-Indoor Area", "Planting Big Trees

19. It was designed with ventilated materials, big trees in the courtyard, semi-indoor area at the elevated floors and reuse of some old materials for demonstration, these are consistent with the concept of energy conservation. 
in Terrace", "Planting Trees around Building", "Natural Materials", and "Modular or Knock-Down System". These architectural elements allow the occupant to remain in the building without air conditioners.

The architectural elements of energy conservation for transformation are: "Efficient Technology to Control Air Quality integrated with Grouping Functional Area", "Insulation Materials", and "Green Innovation: Vertical Garden, Turf Block". These building technologies were developed to support the way of life and complicated new functional areas.

It can be concluded that energy conservation architecture is a design that integrates several energy saving methods as a whole, and the case studies showed Thai architectural inheritance. Most of the architects design buildings based on a passive design concept and green concept, which is also a Thai architecture design concept of inheritance. In the integration of knowledge, they hope to build energy conserving buildings until they are self-sufficient buildings. Hoewver, these need capital for design and construction, so it was found that not too many firms were willing to invest in such public buildings, financial buildings and office buildings, etc.

\section{Acknowledgments}

Thanks to the Thailand Research Fund for the research project "The Creation of Modern Thai Architectural Identity", the big research project that has 6 sub research project including: "Fundamentals of Thai Architectural Identity", "Architectural Composition, Form and Scale/Proportion", "Architectural Features and Refinement", "Architectural Configuration", "Modern Thai Architecture under Globalization and Localization", and "Green Architecture and Sustainable Development". Thanks to Professor Dr. Vimolsithi Horayangkura, head of the research project and research committee who contributed to and pushed this research forward. Important thanks to Thammasat University for providing scholarships to distribute some knowledge from the research.

\section{Bibliography}

Boonyatikarn, Soontorn. Energy efficient home design technique for better quality of life. Bangkok: Property market co., ltd, 1999.

Boonyatikarn, Soontorn. Integrated Design Approve: Shinawatra University. Bangkok: G M Max Media, 2002.

Boonyatikarn, Soontorn. Bio-Solar home: It is power by the Sun. Bangkok: Chulalongkorn University Press, 2004.

Department of Meteorology. Relative Humidity. http://bit.ly/2zkO4CB [Accessed June 17, 2014].

Faculty of Architecture. Chulalongkorn University Alumni Association. $a+A 07$ : Dharma House. Bangkok: Amarin Printing \& Publishing Pcl., 2011. 
Givoni, Baruch. Passive and low energy cooling of building. New York: Van Nostrand Reinhold, 1994.

Horayangkura, Vimolsithi, Boosakorn Settaworakit and Vira Inpantang. The Creation of Modern Thai Architectural Identity: Fundamentals of Thai Architectural Identity. Bangkok: JBP Center Co., Ltd., 2015.

I-Urban. Lanna Rice Barn Homestay. 2013. http://bit.ly/2AsfIvh [Accessed April 28, 2014].

Jaijongrak, Ruetai. Ruen Thai Derm. Bangkok: Thammasat University printing house, 2000.

Mcmullan, Randall. Environmental Science in Building. New York: Palgrave Publishers Ltd., 2002, 345.

Srisutapan Awiroot and Panjira Tisawipat. Daylight in Architecture. Patumthani: Thammasat University Printing, 2009, 49-59.

Sukawattana, Kaiseang. Suan Thai. Bangkok: Chulalongkorn University printing house, 1996.

Thai Green Building Institute. Thai's Rating of Energy and Environmental Sustainability for New Construction and Major Renovation. Bangkok: TGBI, 2013. 
